\title{
Research on the Management Mechanism of the Colleges and Universities Students' Hostel
}

\author{
Anbo Zheng ${ }^{1, \text { a }}$ \\ ${ }^{1}$ College of Automobile \& Civil Engineering, Beihua University, Jilin 132013, China. \\ aanbo_zheng@163.com
}

\begin{abstract}
Keywords: Colleges and Universities, Students' Hostel Management, pattern.
\end{abstract}
\begin{abstract}
China's reform of higher education and improve of material culture in universities reveals many deficiencies gradually and affect students' hostel educational management to work vigorously to promote. The theoretic mode and the practical frame for the Colleges and Universities Students' Hostel Educational Management Pattern is the constructed by analyzing the actual conditions and analyzes deeply the main problem. The new strategic concept of the Colleges and Universities Students' Hostel Educational Management Pattern is advance and just like guiding ideology, guiding principle, main content, strategic priority, structure step etc.
\end{abstract}

\section{Introduction}

College dormitory education management refers to the relevant full-time university authorities in accordance with established objectives and rules and regulations, by certain quarters education and ideological education management mechanism to regulate and standardize the ideological and coordination of activities to promote good school spirit, wind round the formation, in order to achieve management education, service education purposes. That is the reason some thought to integrate science education dormitory management, so that the invisible spiritual forces into tangible physical sense, so that the hostel ideological education more specifically, visualization.

Teachers, teaching materials and laboratory equipment is certainly the first condition is the implementation of teaching, but without good housing management education for the students to create a good living environment, not only is not conducive to students' ideological education and spiritual civilization, and even affect the quality of teaching, education impact talents. From this perspective, dormitory management is not just a simple logistical work, but with the teaching plan complementary organic unity. It closely with school students 'knowledge of the education system for students to open up "second class", so that students in a structured, forms of special environment to live, study, rest, bears the burden of students' ideological education and spiritual civilization construction ; by the students food, clothing, shelter, supervision and other aspects of the line, guidance, management, should influence the external behavior of the students, so that students have a sound mind, good quality and sound personality. Dormitory management is good or bad, a direct impact on the formation of consciousness of students, conduct training, outlook on life and values. Therefore, dormitory management education schools to implement comprehensive education of students important part in educating people in colleges and universities in a prominent position.

Mode refers to the standard style or standard form of something people could follow suit. "College dormitory education management mode, is refers to certain ideas, management theory to guide education in the college dormitory in this particular environment stability of structural forms, expand educational management process. dormitory education management model is the premise of the student dormitories of educational management system, many factors determine its social system, school size and school management system, etc. by educational management mode is appropriate, we can give full play to the student dormitory management performance, the full realization of education has an important impact on management objectives. with the deepening of the reform of universities' social logistics, to the management of the college dormitory education have a huge impact, domestic Universities were combined school situation and to explore a variety of reforms, in the presence of various forms of education management mode, such as the establishment of student housing 
management offices, building student residents committee, set up student life park management office.

\section{Features and Content of Higher Education Student Dormitory Management Model}

Multiple-oriented features. College dormitory created by a beautiful environment and culture for students plays a subtle role in guiding a profound impact on each student's values, moral values, habits, lifestyle choices. Positive, unique hostel management education, students have a strong sense of identity and equal participation of a wide range, large mutual binding and other advantages, it is inspiring, guiding students to stay wide participation, promote civilized fashion, culture comprehensive ability, mutual arsenic will grind , constraints regulate behavior, so the multi-oriented characteristics significantly, to play a full role.

Develop education features. Pay attention to develop education, students good habits and lifestyle, it is an important part of college students quality education. Healthy, progressive, full of thoughtful, informative, interesting hostel management education, is bound to inspire students to understand concepts, cultivate sentiments of students, enrich students 'spiritual and cultural life, develop students' interests, hobbies; bright and clean dormitory and homelike environment atmosphere, a wealth of activities and a harmonious and healthy relationships, good order and pleasing delightful environment will radiate a strong appeal and cohesiveness, encouraging students to proactive, diligent study, and then to develop a strong will, cast noble morality. Human behavior depends on his habit. Fostering habits will not happen overnight, but can not develop good habits while on a pier, it will take hard work. Students 'hostel as the most active, the most closely interlinked sites, should influence the formation of students' personality traits, may lead both in a good atmosphere in the students to establish a correct outlook on life and values, keeping optimistic, positive enterprising mental state, but also may be due to picking up environmental thinking to bring some negative impact behavior and habits and so on, so that some students develop a weird character and habits, and even the formation of a small group, a small circle of influence and others normal exchange and communication. College dormitory management dormitory workers should reach deep into the middle of the students, and they Cuxitanxin exchange views on life and life experience to understand their dynamic thinking and behavior, to develop a set of effective management of dormitory education rules and regulations, to enable students to conduct effective constraints and norms. More importantly, through the constraints and guidance to help students establish good order of life, and create a lively yet rigorous, standardized and have vitality of life situation, so that students learn self-build specifications, self-reflection and self-transcendence, to develop good habits and behavior.

\section{Situation of College Dormitory Educational Management Pattern Analysis}

Construction of the college dormitory education management, understand the status of the college dormitory management education is an essential starting point and foundation. Only by upholding the theory of history, and two points dichotomy, both had seen the college dormitory education management reforms have achievements and advantages, but also face up to problems and deficiencies exist in reality, and to make a fair, realistic analysis, in order to build mode to provide accurate basis.

In East China, focused on understanding the situation of the College of Zhejiang University, Tongji University, Fudan University, Shanghai Foreign Trade University. In the adaptation of logistics socialization reform background, as do Student Administration has done a lot of exploration work, especially the work of the CPC Shanghai Municipal Education Commission, Shanghai Municipal Education Commission jointly in these areas in January 2007, made a "implementation opinions on further strengthening College student life Park ideological and political education and management," and proposed to further strengthen the Shanghai College student life Park ideological and political education and management, and effectively improve the relevance and effective ideological and political education work better play the educational function of campus life, campus 
for the students to create a harmonious environment, promote the overall development of students. But the college student dormitory management reality remains to be seen.

In the Northeast, focused on understanding the educational management of student accommodation, Shenyang University, Dalian University of Technology, Harbin Institute of Technology, Northeastern University, several colleges and universities. These colleges and universities to do the work in the hostel, although proposed to be "managed, service, education" three-pronged, but how to make the ideological and political education work and dorm effective combination, there is a big difficulty, particularly in the education of students management of power and lack of checks on the students' evaluation of power.

Wherein Shenyang University community management made a useful exploration in the process of accommodation students behavior management, the Shenyang University attaches great importance to carry out students' ideological education work, counselors stationed in student dormitories, founded chat association room, organize cultural activities for students to evaluate the performance of the school year, and is responsible for all matters dormitory management (including management staff), working in close coordination with the dorm, co-led by the community management office, to complement each other. Students set up a self-managed team, set up in the dormitory Students' Party Branch, the students, the establishment of branch groups on each floor, each bedroom group set up groups so that students will be fully self-education, self-management, self-restraint, self-service, students play the role of bridge and tie cadres advanced and exemplary role. Also gradually improve student cadres regular system, evaluation system, check the sleep system, regular feedback to the colleges wide publicity to every member of every floor dormitory glory ideology by student leaders, these efforts to make students feel that they are the owner of the hostel, the hostel is my home, a supporter of the management and service participants. So change the past, from "thousands of people in possession of a" unilateral management to "thousands of people a condominium home" common service orientation.

\section{Construction of University Dormitory Education Management Model}

In China, all social science research must have Marxism, Mao Zedong Thought and discussion, Deng Xiaoping Theory and the "Three Represents" as the guidance, research student dormitory management model is no exception. The difference is that the content of each discipline to guide the "basic principle" is not exactly the same or not the same. Leaders of the CPC central idea is the development of education to build a group of college students' dorm education management mode, development of the soul. The healthy development of China's socialist market economy, the knowledge economy on the horizon, requires the College dormitory management education must be clear characteristics of the times and to predict its development trend of the times for higher education management requirements; must establish a comprehensive and wide open drawing on ideas, drawing particular attention to domestic and foreign construction and logistics College student dormitory beneficial experience educational management mode; you must run through ideological system, adhere to the scientific proof, the overall design, the overall balance and coordinated development. Correctly handle local and global, immediate and long-term relationships and may need to educate management on the national higher education system reform this large to consider and plan. The basic idea of guiding student research dormitory education management model, one principle of dialectical and historical materialism, which is the study of the most fundamental principles of student dormitory management model must be followed; the second is Marxism, Mao Zedong Thought, Deng Xiaoping Theory and " Three Represents, 'discussion of education theory, which is research-oriented hostel educational management model is produced accurately reveal the law of development of student dormitory management education itself and from contact with the external environment, the search for student dormitory management mode the right way.

Construction of the college dormitory education management mode to the scientific outlook on development, quality education as the theme, adhere to the people-centered education, moral education first, to coordinate the development of the main line, system and mechanism reform as 
impetus, both in line with our Higher national conditions and the socialist universities, but also give full consideration to the size of the university, the degree of socialization of logistics reality, highlighting the relevance, effectiveness and adaptability, is conducive to different schools, different students grow and mature. College dormitory management education to meet the socialist orientation, should be conducive to the construction of socialist spiritual civilization, in favor of qualified personnel training. How to strengthen students' dormitory management education to students to create a good living and learning environment, this is an issue of common concern Universities. In terms of the subjective consciousness of students, the majority of students to think positive, enthusiastic participation in management, but there are a few students disciplined protect public property, to participate in community service in terms of the lack of consciousness. As an officer of higher education, students are in higher education, a place to stay for many years in a "dirty and messy" situation is not conducive to the construction of school spirit, but also for the healthy growth of the younger generation will have a negative physical and psychological impact. By building the college dormitory management education, advocacy and establish a socialist ideas, new fashion, to enable students to become dormitory spiritual civilization construction sites, in order to promote the training of personnel.

\section{Summary}

Focus dormitory management tasks is to pass thorough and painstaking ideological and political education to nurture students to become a political firm, good moral character, demeanor civilized qualified personnel in the new century. University Students' Apartment Management As changes in the social environment changes. With the political system, economic system, educational system, especially in Logistics Socialization Model of intervention, the objective has changed the living conditions of university students, improving dormitory life functions, but longs management, profit-seeking instinct weakened dormitory education Features. Logistics Management believe that their duty is to pipe hardware construction and health inspection, other work should be managed by them; student affairs administration believes the student accommodation fee logistics department, dormitories affairs should be managed by them, even if the student affairs department to manage, because there is no relevant rights, some of the work progress of the effect is not obvious. Currently more mainland college students dormitory jointly managed by multiple departments Security Department, Logistics Group, Student Affairs Office, and other departments, fragmented, difficult to clear division of labor, resulting in some wrangling pushed induced phenomenon, inefficiency, resulting in student dormitories mismanagement became a "free zone." Distinguish duties, straightening out relations, it is to improve students' dormitory management efficiency a priority.

\section{References}

[1]Hou Wenhua. "On campus Student Life Education Management System" ideological and theoretical education 2004.3

[2]Tang Xusheng other "Students Residents Committee: New Model of Student Community autonomous management of a Shanghai Foreign Studies

[3]Li Shiqiong. "Student Community Political Education," China Outstanding Dissertation full text databases, 2005.8

[4]Lin Hui Branch. "Community Cultural Construction of College Students' TRIBUNE, 2004.4

[5]Huangbu Jun, Huang Qiong. "Students Create A civilized community life", Nantong Institute of Technology, 2004.3 